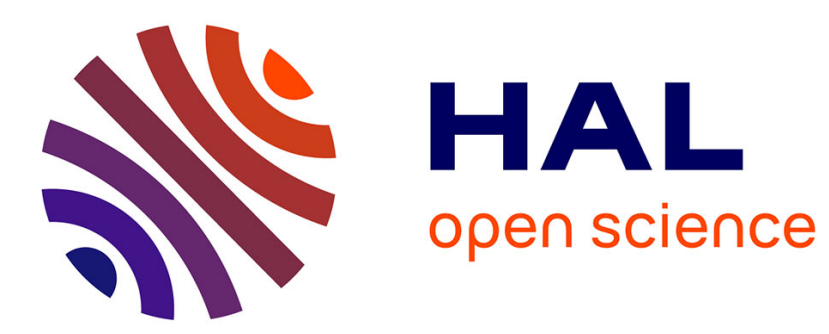

\title{
The role of stability and moisture in the diurnal cycle of convection over land
}

Jean-Pierre Chaboureau, F. Guichard, J.-L. Redelsperger, J.-P. Lafore

\section{To cite this version:}

Jean-Pierre Chaboureau, F. Guichard, J.-L. Redelsperger, J.-P. Lafore. The role of stability and moisture in the diurnal cycle of convection over land. Quarterly Journal of the Royal Meteorological Society, 2004, 130, pp.3105-3117. 10.1256/qj.03.132 . hal-00268050

\section{HAL Id: hal-00268050 \\ https://hal.science/hal-00268050}

Submitted on 8 Jul 2021

HAL is a multi-disciplinary open access archive for the deposit and dissemination of scientific research documents, whether they are published or not. The documents may come from teaching and research institutions in France or abroad, or from public or private research centers.
L'archive ouverte pluridisciplinaire HAL, est destinée au dépôt et à la diffusion de documents scientifiques de niveau recherche, publiés ou non, émanant des établissements d'enseignement et de recherche français ou étrangers, des laboratoires publics ou privés. 


\title{
The role of stability and moisture in the diurnal cycle of convection over land
}

\author{
By J.-P. CHABOUREAU ${ }^{1,2 *}$, F. GUICHARD ${ }^{1}$, J.-L. REDELSPERGER ${ }^{1}$ and J.-P. LAFORE ${ }^{1}$ \\ ${ }^{1}$ CNRM/GAME, Météo-France and CNRS, France \\ ${ }^{2}$ Laboratoire d'Aérologie, Université Paul Sabatier and CNRS, France
}

\begin{abstract}
SUMMARY
The diurnal cycle of convection over land is investigated by a cloud-resolving model simulation. Three regimes of convection - dry, shallow, and deep — successively take place during daytime under the presence of substantial convective available potential energy. The convective inhibition (CIN) and the normalized saturation deficit (NSD) in the cloud-base layer are identified as the major two variables that characterize the cycle of the convective regimes. The surface heating during daytime leads to the development of a quasi-dry well-mixed convective planetary boundary layer (PBL). This yields a decrease of CIN while NSD remains steady. Shallow convection is initiated as soon as the CIN becomes lower locally than the vertical kinetic energy in the PBL. This timing also marks the minimum of CIN, both in local and in domain-mean senses. Then, detrainment of moisture from the cloud layer gradually moistens the low free troposphere, resulting in a NSD decrease. Finally, deep convection is triggered when sufficient moistening is realized, as measured by a NSD minimum. During deep convection, NSD rapidly increases and CIN increases. Once CIN has exceeded the vertical kinetic energy in the PBL, deep convection ceases.
\end{abstract}

KEYWORDS: Convective inhibition Saturation deficit

\section{INTRODUCTION}

The diurnal cycle of moist convection is of major importance for climate studies due to its strong radiative feedbacks, the resulting precipitation, and its control on surface temperature. The diurnal cycle of convection is stronger over land than over oceans, and strongest during summer. Over continents, convection usually occurs in the late afternoon or early evening under a dominant influence of daytime boundarylayer heating (Wallace 1975; Duvel 1989). The diurnal cycle varies regionally due to the modulations of low-level convergence by land/sea and mountain/valley breezes as well as mesoscale features (Yang and Slingo 2001; Nesbitt and Zipser 2003). Recent studies have shown deficiencies in general-circulation models (GCMs) for capturing the diurnal cycle of deep convection, both in magnitude and phase (Dai et al. 1999; Lin et al. 2000; Yang and Slingo 2001; Bechtold et al. 2004). Especially, deep convection in GCMs tends to be in phase with low-level temperature and atmospheric instability as measured by the convective available potential energy (CAPE), and thus it tends to occur earlier than observed. This is a well-established deficiency in global models, suggesting their fundamental shortcomings in parametrizing the surface, boundary layer, and convective processes.

However, comprehensive studies describing the diurnal cycle of deep convection at convective scale are still missing. The relationship between CAPE and convection is not so straightforward as often claimed. Both are clearly linked on a climatological scale, but the situation is much less simple at shorter scales. For instance, in the tropical western Pacific, Sherwood (1999) found that for $90 \%$ of the time there is enough CAPE for convection, which is only $20-30 \%$ likely to break out. Other factors appear to play a role, such as the convective inhibition (CIN) and the moisture field, as pointed out by Brown and Zhang (1997), Mapes (2000), Parsons et al. (2000) and Redelsperger et al.

* Corresponding author, present affiliation: Laboratoire d'Aérologie, Observatoire Midi-Pyrénées, 14 av. Belin, 31400 Toulouse, France. e-mail: chajp@aero.obs-mip.fr 
(2002). Over land, where much stronger interactions are found between the diurnal cycle of radiation and the boundary-layer properties, CAPE alone cannot explain the observed timing of convection. Therefore, the main objectives of this study are: (i) to identify why the occurrence of deep convection is delayed with respect to the diurnal cycle of boundary-layer heating and of the induced atmospheric stability, and (ii) to interpret these findings in terms of appropriate factors that can be used by parametrizations.

The present approach is based on the analysis of an idealized diurnal cycle over land, in which couplings between the boundary layer and deep convection are examined. The simulated time series shows a well-defined succession of regimes, beginning with clear-sky boundary-layer convection in the morning, followed by relatively shallow nonprecipitating clouds. Then, a few hours later, the onset of deep convection occurs. The focus of this study is on the mechanisms that control this succession of distinct regimes. The 4-day simulation provides four different realizations of diurnal cycles, which allows us to assess the robustness of the analysis. In the following, section 2 presents the model and the idealized case. Section 3 analyses the results from the simulation. Section 4 concludes the paper.

\section{THE MODEL AND THE IDEALIZED CASE SET-UP}

The cloud-resolving model (CRM) used is the non-hydrostatic mesoscale model Meso-NH (Lafore et al. 1998). In this study, the following parametrizations have been activated: the one-and-a-half turbulent scheme implemented by Cuxart et al. (2000) based on the physical mixing length of Bougeault and Lacarrère (1989), the subgrid condensation scheme of Chaboureau and Bechtold (2002), the revised radiative scheme used at European Centre for Medium-Range Weather Forecasts (ECMWF, Gregory et al. 2000) including the Rapid Radiative Transfer Model (RRTM) parametrization (Mlawer et al. 1997), and a prognostic microphysical scheme for five precipitating and nonprecipitating liquid and solid water categories (Pinty and Jabouille 1998). The model was run on a large two-dimensional domain including 256 horizontal grid points with a spacing of $2 \mathrm{~km}$, and 47 vertical levels between the surface and the model top at $25 \mathrm{~km}$, with a grid spacing ranging from $70 \mathrm{~m}$ near the surface to $700 \mathrm{~m}$ in the free troposphere. The model time step was $8 \mathrm{~s}$.

Note that this grid size does not allow a proper resolution of shallow convection. In the present simulation, it is handled, for a significant part, by the subgrid condensation and turbulence schemes. Furthermore, simulation tests with horizontal grid spacing ranging from $4 \mathrm{~km}$ to $250 \mathrm{~m}$ have shown no specific delay in precipitation when decreasing the resolution, contrary to the results of Petch et al. (2002). This difference is possibly due to the differences in the turbulent schemes and/or the use of a subgrid condensation scheme in the present simulation.

We used the case (Guichard et al. 2004)* that was derived from a continental midlatitude convective case observed during the Atmospheric Radiation Measurement (ARM) experiment, corresponding to the first day of the ARM-Global Energy and Water-cycle Experiment Cloud System Study (GCSS) Working Group 4 Case 3 subcase A from 1130 UTC 27 June 1997 to 1130 UTC 28 June 1997 (see the intercomparison studies between CRMs by Xu et al. (2002) and between single-column models by Xie et al. (2002)). This idealized case was built in order to address more directly the modelling problems encountered with the diurnal cycle of convection over land (Guichard et al. 2004). In brief, the specified tendencies are the large-scale vertical

* Initial conditions are available on http://www.cnrm.meteo.fr/gcss/EUROCS/EUROCS.html 


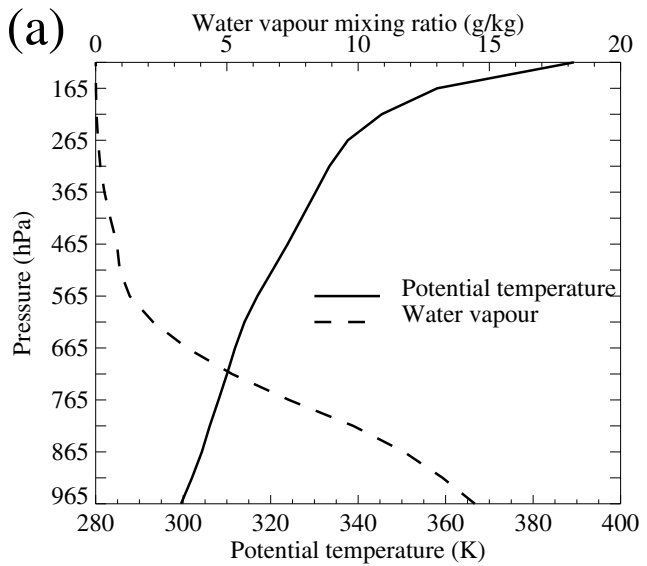

(b)

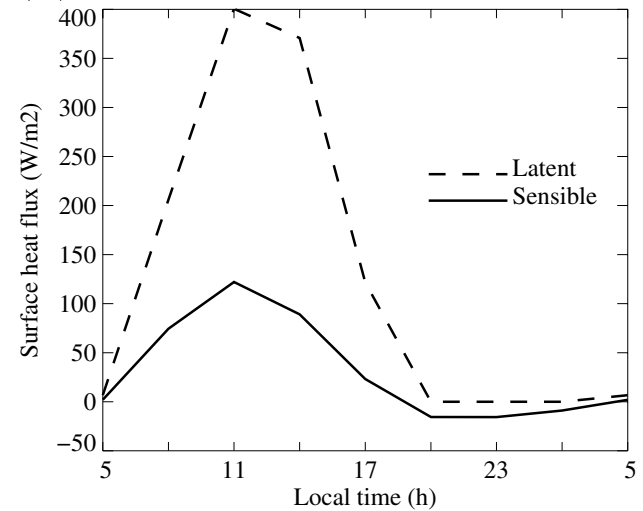

(c)

(d)
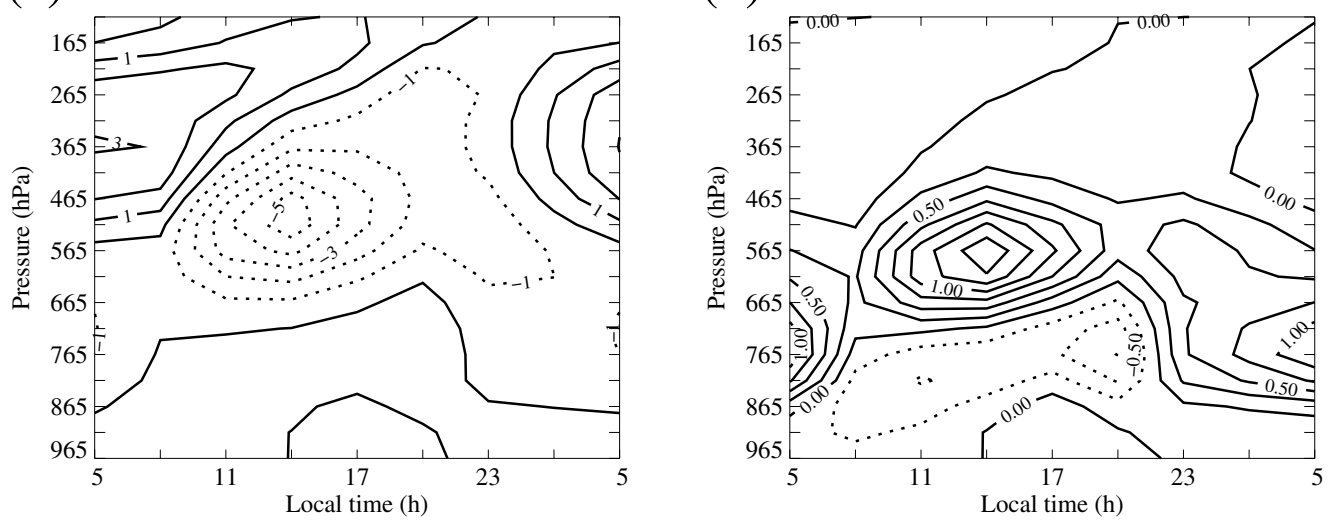

Figure 1. Imposed model conditions: (a) initial profiles of potential temperature and water vapour mixing ratio, (b) time series of prescribed surface sensible and latent heat flux, and time-height cross-sections of large-scale vertical advective tendencies of (c) heat $\left(\mathrm{K} \mathrm{day}^{-1}\right)$ and (d) moisture $\left(\mathrm{g} \mathrm{kg} \mathrm{day}^{-1}\right)$.

advection of temperature and moisture as derived from variational analysis (Zhang and Lin 1997). The surface latent and sensible heat fluxes are obtained from measured total surface heat fluxes, divided into latent and sensible heat parts using the Bowen ratio (sensible over latent heat flux) provided by the analysis. As a consequence of these differences with the exact set-up of subcase A, the results of this idealized simulation are not expected to match systematically the ones obtained by Xu et al. (2002).

It should be noted that the framework of this case, including the choice of prescribed and weak large-scale advections of heat and moisture, implies that the development of convection will mostly occur in response to the destabilization of the lower levels induced by the surface heat fluxes. Implicit to such a choice is the assumption that the prescribed large-scale advections, either weak or strong, are the ones 'in equilibrium' with the convective activity, as convection cannot generate feedback on them within this (commonly used) framework. Indeed, prescribing the forcings ensures a strict control of the energy input to the system.

The model is initialized by an area-average sounding (Fig. 1(a)). A small random temperature perturbation of $0.2 \mathrm{~K}$ is added to this horizontally-uniform initial condition at the first model level in order to initiate convection. Horizontal boundary conditions 
are periodic. The vertical advective tendencies of temperature and moisture and surface fluxes are specified from the observations (Figs. 1(b), (c) and (d)). The domain-averaged horizontal winds are nudged towards the observed values with a nudging time of 2 hours. Model outputs are every 12 min.

\section{RESUlts}

\section{(a) Overview of the diurnal evolution}

The diurnal evolution obtained from the simulation is shown in Fig. 2. The total surface heat flux (sensible plus latent), prescribed in the model, reaches a minimum of $-15 \mathrm{~W} \mathrm{~m}^{-2}$ at $23 \mathrm{~h}$ local time and a maximum of $530 \mathrm{~W} \mathrm{~m}^{-2}$ at $11 \mathrm{~h}$ (Fig. 2(a)). Each day, precipitation begins slightly after noon, and lasts until $18 \mathrm{~h}$. In other words, convective rainfall also exhibits a diurnal cycle, but lagged with respect to the one of surface heat fluxes and solar radiation, with a rainy period usually shorter than the daytime interval, and no rainfall during the morning hours. However, some differences are noticeable among the four days of simulation. Day after day, the onset of precipitation becomes gradually earlier. During the last three days, rainfall reaches its maximum intensity faster, and the decrease is then more gradual. During the afternoon/evening of the last two days, one can even notice that the rainfall and surface heat fluxes exhibit a similar rate of decrease (the two curves are close to each other in Fig. 2(a) during these periods).

From sunrise to $12 \mathrm{~h}$, a well-mixed convective boundary layer grows in response to the surface heat fluxes, as shown by the time-height section of virtual potential temperature (Fig. 2(c)). The planetary boundary-layer (PBL) height* reaches more than $1000 \mathrm{~m}$ at $14 \mathrm{~h}$. Under these relatively low Bowen ratio values (of the order of 0.3 ) the lifting condensation level (LCL) remains below the PBL height (Fig. 2(c)). The increase in temperature and humidity also leads to an increase of CAPE and a decrease of CIN (Fig. 2(d)). Here, CAPE and CIN are computed for each grid column and averaged over the whole domain. (Similar values of CAPE and CIN are obtained when computed from the domain-mean values of temperature and humidity; see Fig. 3 in Guichard et al. 2004.) They are based on the pseudo-adiabatic ascent of an air parcel whose departure level (DPL) varies from 110 to $510 \mathrm{~m}$, corresponding to the lowest $50 \mathrm{hPa}$ above the ground level (AGL). CAPE is defined as the vertical integral of the liftedparcel buoyancy from DPL to the level of neutral buoyancy (LNB), whereas CIN is the absolute value of the negative contribution to the same vertical integration. LNB is defined as the highest level where the buoyancy turns from positive to negative.

At $11 \mathrm{~h}$, the first shallow clouds appear. The LCL lies just below the PBL top, CIN is at a minimum (less than $10 \mathrm{~J} \mathrm{~kg}^{-1}$ ), and the vertical kinetic energy maximum of the layer between 110 and $510 \mathrm{~m}$ (the maximum of the resolved vertical kinetic energy plus the turbulent kinetic energy) exceeds $1 \mathrm{~J} \mathrm{~kg}^{-1}$. As detailed in the next subsection, because CIN locally takes values less than $1 \mathrm{~J} \mathrm{~kg}^{-1}$, the locally-given maximum vertical velocity is sufficient for lifting an air parcel from the DPL to the LCL. As a result, the first shallow cumulus appear, as shown by the cloud condensate mixing ratio in Fig. 2(b). They lead to moistening above the PBL. A few hours later, the first deep convective cells appear with cloud tops reaching $12 \mathrm{~km}$ AGL and a precipitation rate of more than $20 \mathrm{~mm} \mathrm{day}^{-1}$. The afternoon decrease of surface fluxes and the impact of convective

\footnotetext{
* For the sake of simplicity, the PBL height is computed from the maximum mixing length derived in the turbulence scheme. Indeed, the mixing length is computed as an average of the maximum of upward and downward vertical displacements allowed for a parcel of air having the mean kinetic energy of the level. At midlevel, the mixing length is a maximum and the displacement is equal to half of the PBL height.
} 

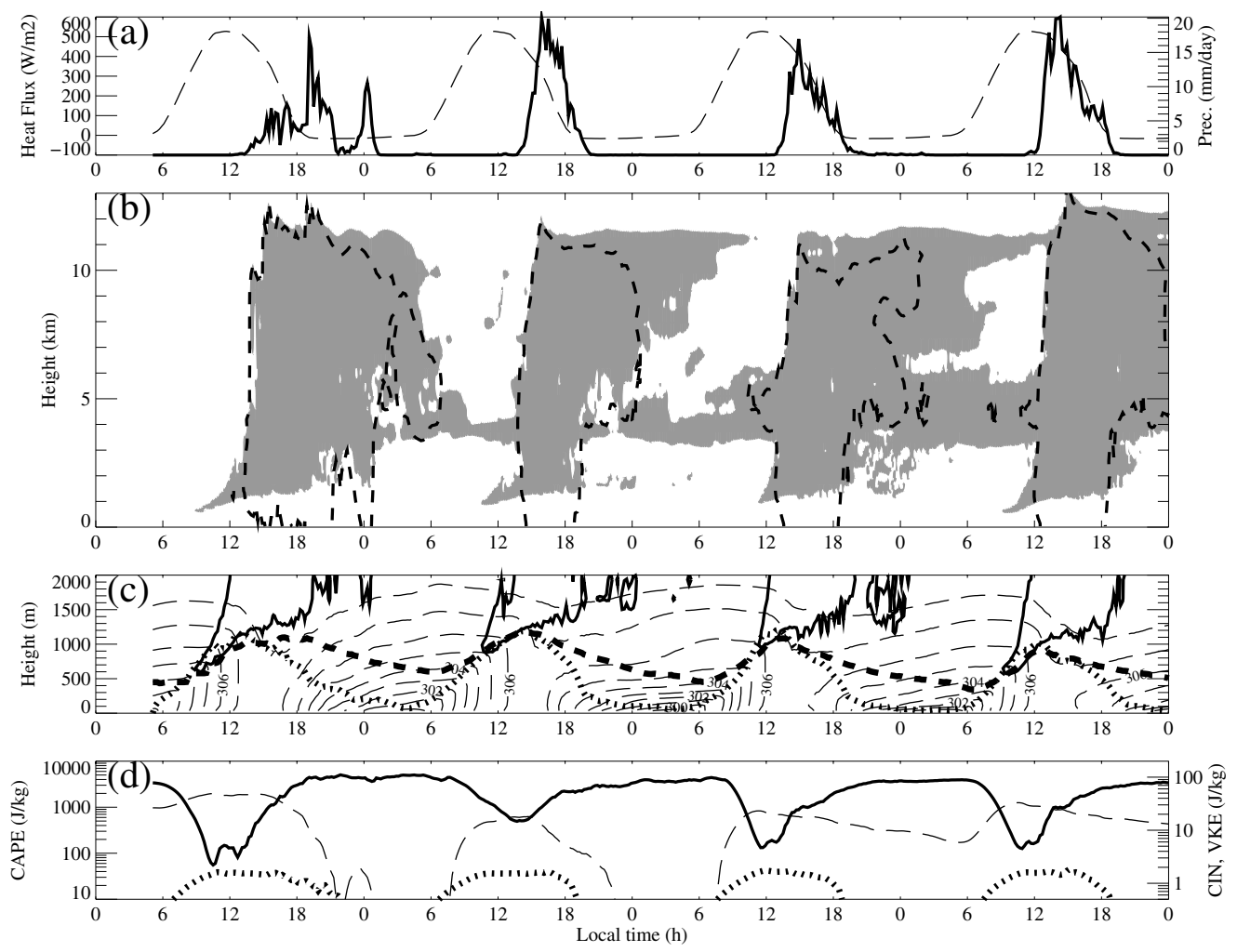

Figure 2. Model evolution over 4 days of: (a) surface heat flux (thin dashed) and precipitation rate (thick solid); (b) tropospheric section of cloud condensate (grey shading) and precipitation (within dashed); (c) boundary layer section of cloud condensate (thick solid), boundary layer height (thick dotted), lifting condensation level (thick dashed), and virtual potential temperature (thin dashed, with contour interval $1 \mathrm{~K}$ ); (d) convective available potential energy (thin dashed), convective inhibition (thick solid), and the maximum of vertical kinetic energy between 110 and $510 \mathrm{~m}$ (thick dotted).

downdraughts on the boundary layer properties both act to reduce CAPE and increase CIN. As a result, deep convection finally ends.

\section{(b) Triggering conditions for shallow convection}

The conditions leading to shallow convection are examined in detail by focusing on the period between 9 and $17 \mathrm{~h}$ (Fig. 3). The first clouds (as shown by cloud condensate greater than $0.01 \mathrm{~g} \mathrm{~kg}^{-1}$ ) appear each day at $9-11 \mathrm{~h}$, a few hours before the beginning of surface precipitation. During these few hours, the base of shallow clouds coincides with the LCL while their top progressively increases, exceeding the level of free convection (LFC). During this period, domain-mean CIN reaches its minimum (less than $5 \mathrm{~J} \mathrm{~kg}^{-1}$, except for day 2), but always larger than the maximum of the vertical kinetic energy between 110 and $510 \mathrm{~m}$, varying between 1 and $2 \mathrm{~J} \mathrm{~kg}^{-1}$. Thus, the air parcel defined by the domain mean never gets enough kinetic energy to overcome CIN. However, CIN as defined by an average over a restricted subdomain can be smaller, even less than $0.1 \mathrm{~J} \mathrm{~kg}^{-1}$, as shown by the first percentile of CIN in Fig. 3(b). CIN decreases before the first cloud appears (except for day 1, the subgrid condensation scheme yielding clouds at $9 \mathrm{~h}$ ). Apart from the first hours of day 1, the standard deviation of CIN is always greater 

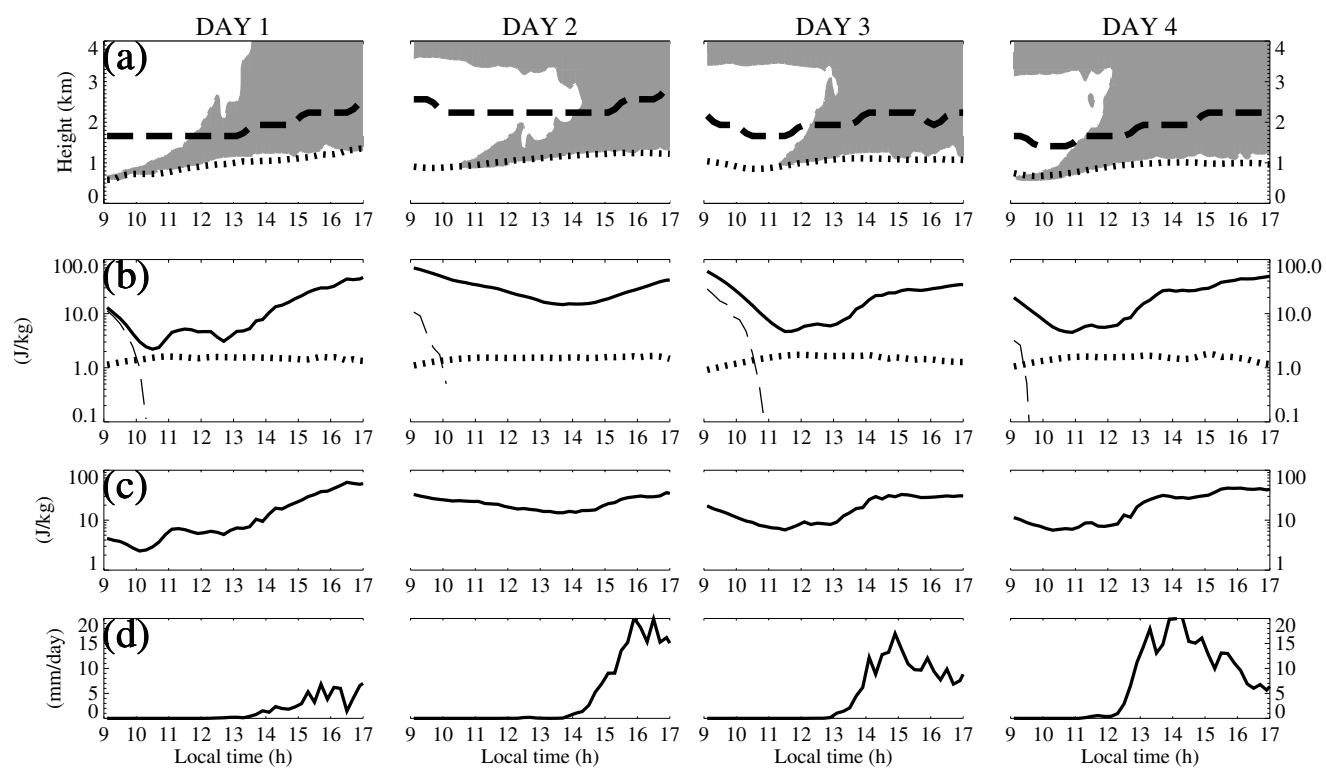

Figure 3. Model daytime (9-17 h) evolution over 4 days of: (a) cloud condensate (grey shading), level of free convection (thick dashed), and lifting condensation level (thick dotted), (b) convective inhibition (CIN, thick solid), maximum of the vertical kinetic energy between 110 and $510 \mathrm{~m}$ (thick dotted), and first percentile of CIN (thin dashed), (c) standard deviation of CIN, and (d) precipitation rate.

than $10 \mathrm{~J} \mathrm{~kg}^{-1}$ (Fig. 3(c)), consistent with the difference between the domain-averaged and the first percentile of local CIN (Fig. 3(b)).

This is further shown by the time evolution of the percentage of grid columns with CIN exceeding threshold values (Fig. 4). Each day, CIN becomes less than $0.1 \mathrm{~J} \mathrm{~kg}^{-1}$ only between 9 and $18 \mathrm{~h}$. The fraction of grid columns with CIN less than $0.1 \mathrm{~J} \mathrm{~kg}^{-1}$ reaches a maximum at $12 \mathrm{~h}$, greater than 5\%. Conversely, during night, the local CIN is always larger than $10 \mathrm{~J} \mathrm{~kg}^{-1}$. With the maximum of the vertical kinetic energy in the PBL of the order of $1 \mathrm{~J} \mathrm{~kg}^{-1}$, convection can be triggered only during daytime, between 9 and $18 \mathrm{~h}$, when CIN can be locally less than the maximum kinetic energy in the PBL.

As already noted, the domain-averaged CIN during day 2 presents larger values than the other days. Consistently, fewer grid columns exhibit low values of CIN on day 2 compared to the other days, and the LFC is also higher (Fig. 3(a)). The PBL is colder and drier than the other days, due to the downdraughts of the previous day, as they still impact on the low levels late during the first night, compared to the other nights (Fig. 2(a)). The occurrence of convective downdraughts late into the first night could also explain why an asymmetry between the rapid increase and the afternoon's more gradual decrease of the percentage of 'low-CIN columns' is found each day except for day 2 (Fig. 4). This asymmetry seems to reflect the distinct characteristics of the processes successively taking place during daytime, from dry to moist precipitating convection.

\section{(c) Transition from shallow to deep convection}

As previously stressed, the onset of deep convection is preceded by a transition period lasting 2-3 hours during which moist convection remains shallow (Fig. 3). Even with a locally negligible CIN, ascending air parcels normally do not systematically reach up to the LNB, located at $12 \mathrm{~km}$ AGL, because they can mix with the drier environment air through entrainment above the PBL (especially on the first day, which is 


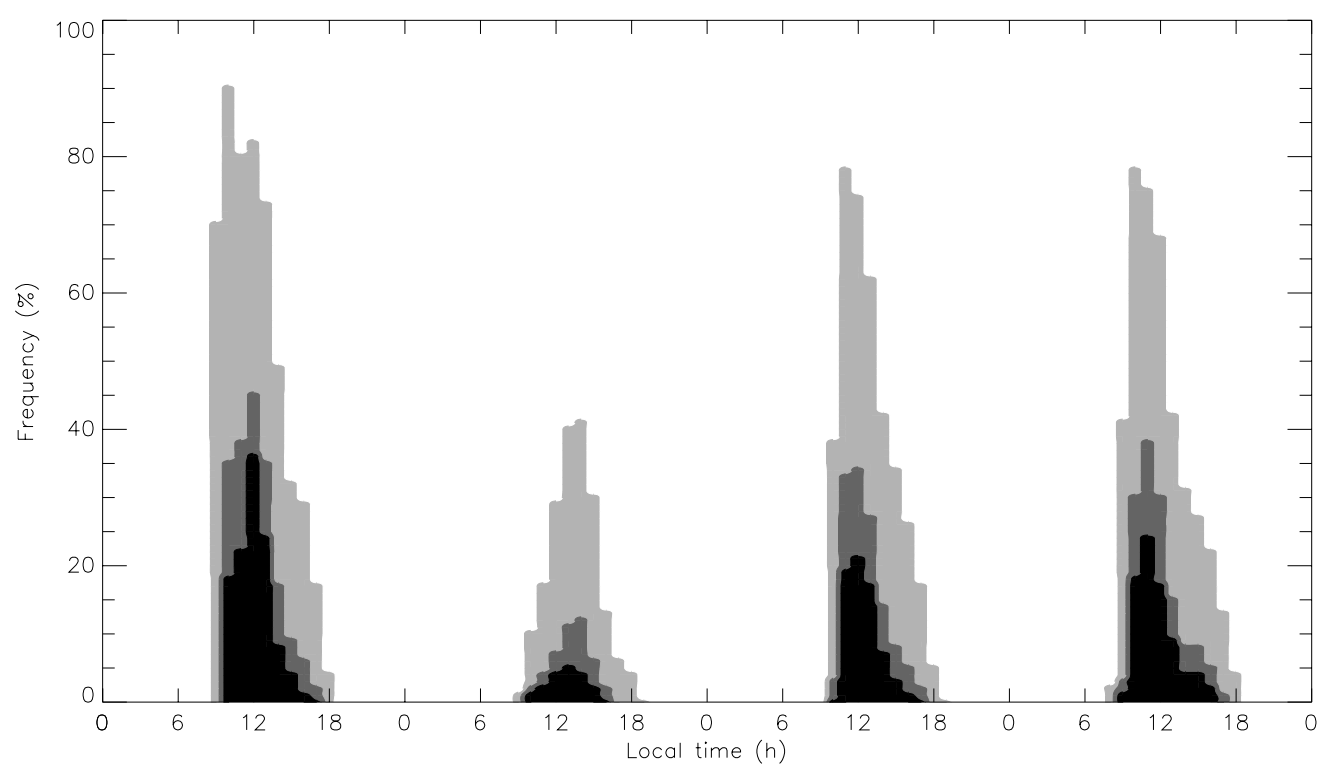

Figure 4. Model evolution over 4 days of percentage of grid columns with values of convective inhibition less than $0.1 \mathrm{~J} \mathrm{~kg}^{-1}$ (black), in the range $0.1-1 \mathrm{~J} \mathrm{~kg}^{-1}$ (dark grey), and in the range $1-10 \mathrm{~J} \mathrm{~kg}^{-1}$ (light grey).

characterized by the driest conditions in the lower free troposphere). A simple measure to quantify this dry-entrainment process is the vapour deficit (Redelsperger et al. 2002), defined as the mean difference between the saturated water vapour mixing ratio $r_{\text {sat }}$ and the water vapour mixing ratio $r$ (Fig. 5(a)). Each day, a moist tongue of reduced values of vapour deficit (less than $4 \mathrm{~g} \mathrm{~kg}^{-1}$ ) appears in a layer located just above the PBL top, also corresponding to the cloud base. Note that the decrease of the vapour deficit with height in the PBL is consistent with the development of a well-mixed PBL. This feature persists but becomes less dramatic each day, because the mean moistening of the free troposphere lowers the $4 \mathrm{~g} \mathrm{~kg}^{-1}$ contour from 4 to $1 \mathrm{~km}$ AGL.

Although the vapour deficit $\left(r_{\text {sat }}-r\right)$ shows some relationship with the cloud development, we need to take into account the sub-domain variability of water vapour. Figure 5(b) presents the standard deviation of vapour deficit $\sigma_{r_{\mathrm{sat}}-r}$. The maximum of variability (more than $1 \mathrm{~g} \mathrm{~kg}^{-1}$ ) indicates the location where the mixing between moist boundary-layer air and dry environmental air from above can occur. Regions of $\sigma_{r_{\text {sat }}-r}$ maxima are close to the surface and at the PBL top before cloud appearance (for days 2 and 3). At $11 \mathrm{~h}$, these regions are observed in the cloudy areas (this broadly delineates the entrainment zone), and finally in the PBL after the onset of precipitation at $14 \mathrm{~h}$.

The occurrence of deeper clouds appears to be related to both a decrease of the domain-mean saturation deficit $\left(r_{\mathrm{sat}}-r\right)$ and an increase of its sub-domain variability above the PBL. For this reason, we consider the normalized saturation deficit (NSD) defined as

$$
\mathrm{NSD}=\frac{r_{\mathrm{sat}}-r}{\sigma_{r_{\mathrm{sat}}-r}}
$$

Examining the time evolution of the NSD (Fig. 5(c)), it is striking that the contour of NSD $=2$ matches well the cloud condensate profile of $0.01 \mathrm{~g} \mathrm{~kg}^{-1}$. It quantifies efficiently the dryness of the troposphere in the morning on day 1 , with NSD $>5$, and the moist layer below $3 \mathrm{~km}$ in the morning of the following days with $2<\mathrm{NSD}<5$. 

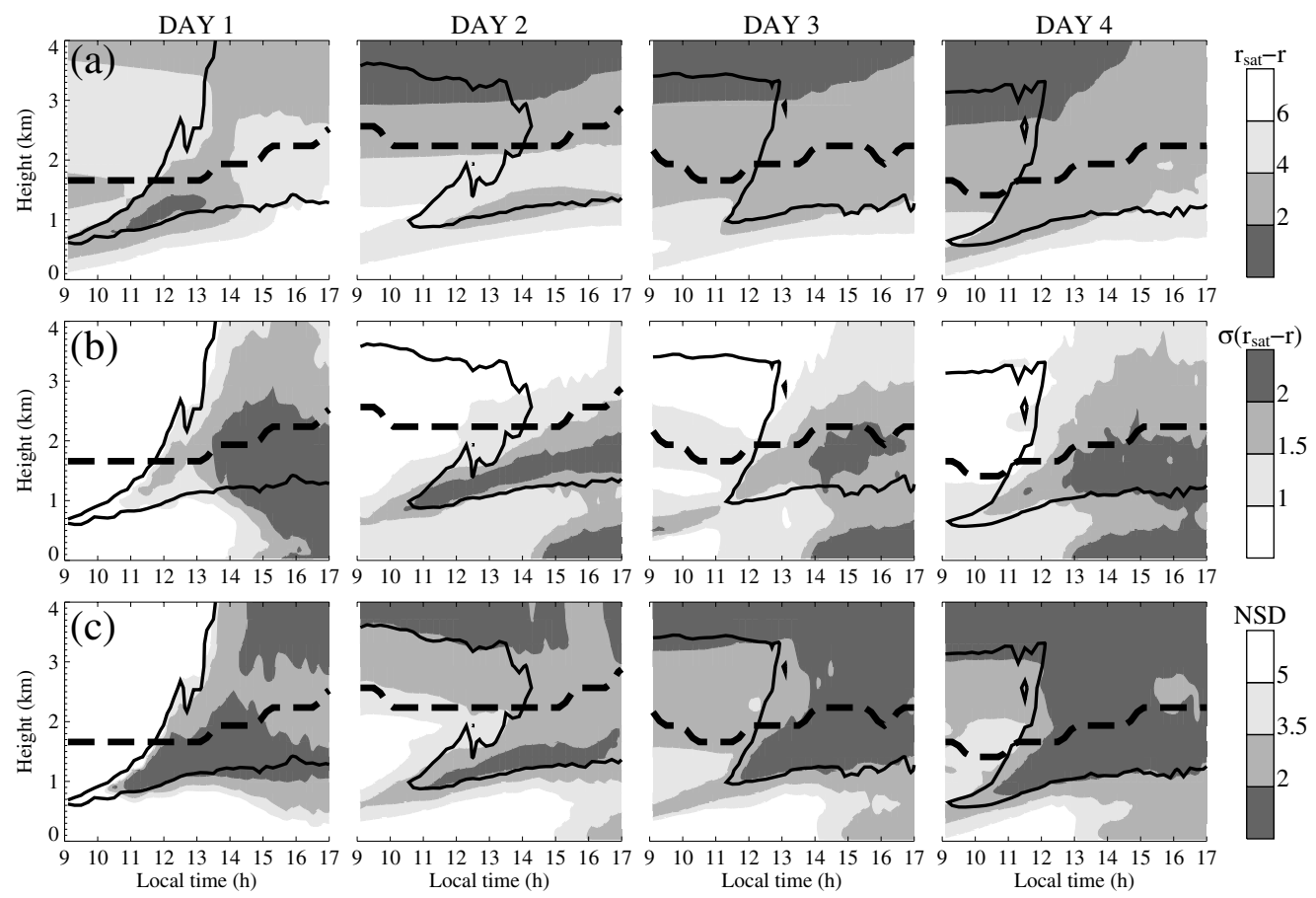

Figure 5. Model daytime (9-17 h) evolution over 4 days of height variation of (a) vapour deficit (shading, contour interval $2 \mathrm{~g} \mathrm{~kg}^{-1}$ ), (b) standard deviation of vapour deficit (shading, contour interval $0.5 \mathrm{~g} \mathrm{~kg}^{-1}$ ), and (c) normalized saturation deficit (shading, contour interval 1.5). Superimposed are the $0.01 \mathrm{~g} \mathrm{~kg}^{-1}$ contour of cloud condensate (thick solid) and the level of free convection (thick dashed).

The downdraughts, associated with larger variability of temperature and water vapour in the afternoon, result in similar values of NSD each day.

In order to further demonstrate our argument, we plot the trajectories from 9 to $17 \mathrm{~h}$ in the phase space of the cloud-top height (based on the threshold of $0.01 \mathrm{~g} \mathrm{~kg}^{-1}$ cloud condensate) and NSD (averaged between the PBL top and the LFC) (Fig. 6). During this daytime period, the PBL top matches the LCL so the layer over which NSD is averaged covers the cloud-base layer. Until noon, NSD decreases, indicating the moistening of the cloud-base layer, while the cloud-top height remains nearly constant at $1-2 \mathrm{~km}$. At $12-13 \mathrm{~h}$, finally, the cloud-top height begins to increase as a result of sufficient moistening of the cloud-base layer. At this point, NSD appears to have reached its minimum possible value, and remains constant afterwards while the cloudtop height rises up to $12-13 \mathrm{~km}$ AGL. This minimum NSD value also appears to indicate a threshold before deep convection develops. Again, day 2 departs from the other days, suggesting a lower threshold close to 2, indicating a drier cloud-base layer, against 1.5 on the other days. An explanation of the existence of such thresholds is that air parcels need to be moist enough to keep their positive buoyancy. The development of convective elements is indeed modified by the entrainment of environmental dry air at a rate roughly proportional to the saturation deficit (Redelsperger et al. 2002).

The previous results imply that convection schemes have to take into account the domain mean as well as the sub-domain variability of humidity in order to handle correctly the growth of precipitating cells. It is striking that some recent statistical cloud schemes have been developed in the same spirit, i.e. by parametrizing the subgrid-scale variability of total water mixing ratio $r_{\mathrm{t}}$ (e.g. Bony and Emanuel 2001; Tompkins 2002). 


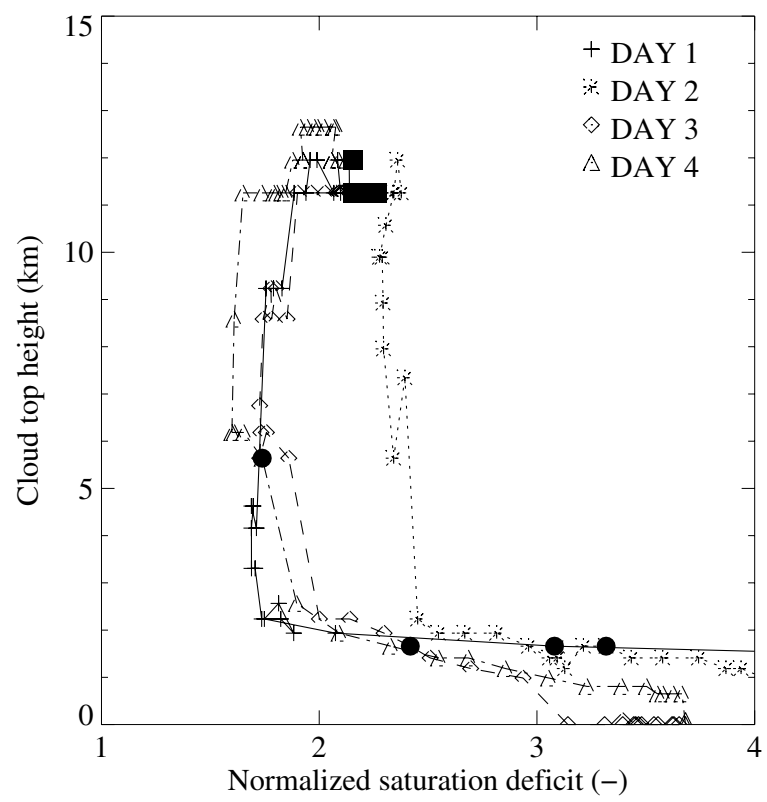

Figure 6. Model evolution over 4 days of cloud-top height as a function of the normalized saturation deficit, averaged between the boundary-layer top and the level of free convection. Points are every $12 \mathrm{~min}$ from 9 to $17 \mathrm{~h}$. Points at $12 \mathrm{~h}$ and $17 \mathrm{~h}$ are indicated by large dots and squares, respectively.

However, not all the sub-domain variability governing the cloud cover is accounted for by $r_{\mathrm{t}}$ or $r$ alone. The effect of temperature variability on saturated water vapour mixing ratio can be significant too for the determination of cloud cover. It was found to be roughly half that of humidity by Tompkins (2003), see also Price and Wood (2002).

\section{CONCLUSION}

A simulation of an idealized diurnal cycle of deep convection over land has been performed over 4 days using a CRM. The prescribed diurnal cycle of surface heating gave rise to a diurnal evolution of the $\mathrm{PBL}$ in phase, and convective precipitation lagged by a few hours.

During daytime, when CAPE is large, three convective regimes-dry, shallow and deep-successively take place. These three regimes are distinguished by two variables, the CIN and the NSD in the cloud-base layer (Fig. 7):

(i) quasi-dry convection with cloud thickness less than $200 \mathrm{~m}$ : CIN decreases while NSD remains steady;

(ii) shallow convection with cloud thickness between $200 \mathrm{~m}$ and $2 \mathrm{~km}$ : CIN remains constant while NSD decreases (moistening in the cloud base layer);

(iii) deep convection: CIN increases due to downdraughts while NSD increases slowly (drying).

During nighttime both CIN and NSD tend to increase.

The same mechanisms appear to work on each of the four days, for the transition from one regime to another. Shallow convection begins when CIN is locally lower than the vertical kinetic energy, coinciding with the minimum of the domain-averaged CIN. Deep convection is triggered once the cloud-base layer is sufficiently moistened by 


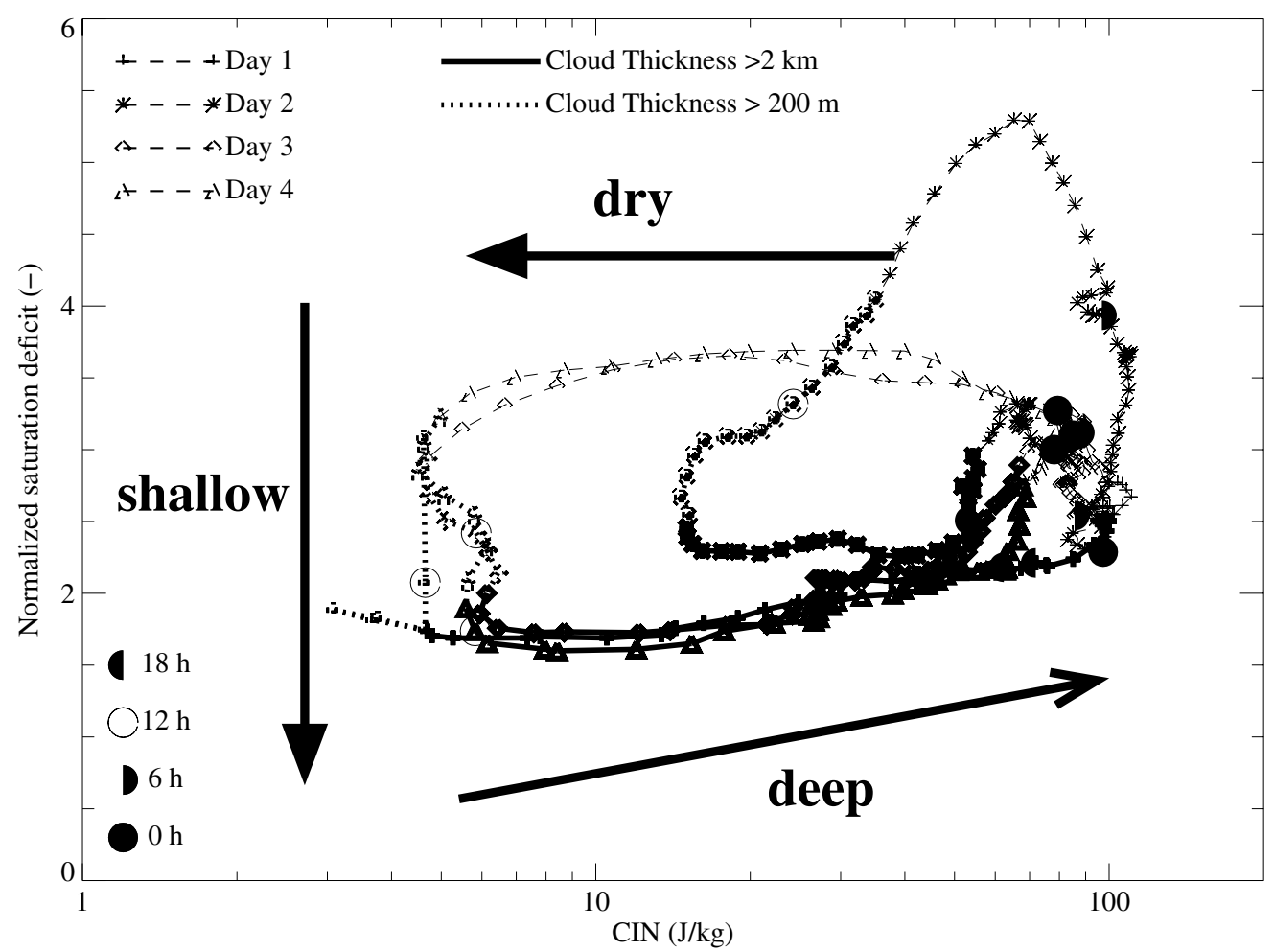

Figure 7. Model evolution over 4 days of normalized saturation deficit, averaged between the boundary-layer top and the level of free convection, as a function of convective inhibition, CIN. Dotted (solid) thick line represents the periods with the cloud thickness greater than $200 \mathrm{~m}(2 \mathrm{~km})$.

detrainment. Deep convection ends when CIN becomes larger than the vertical kinetic energy everywhere in the domain. Notably, day 2 follows a quantitatively different path, with drier and colder conditions, but careful analysis indicates that identical mechanisms still occur.

The present work has investigated the mechanisms needed to be represented in the corresponding parametrizations, in order that GCMs properly capture the diurnal cycle of deep convection over land. Those include a well-marked transition between shallow and deep convection, a convection trigger function linking CIN and kinetic energy in the PBL, and sufficient moistening of the lower free troposphere before deep convection can occur. Subgrid-scale variability needs to be taken in account in GCMs. Some recent developments of cloud schemes have included various representations of subgrid-scale fluctuations of humidity (e.g. Bony and Emanuel 2001; Chaboureau and Bechtold 2002; Tompkins 2002). Chaboureau and Bechtold (2002) proposed a simple parametrization of a normalized departure from mean saturation $Q_{1}{ }^{*}$ (Mellor 1977; Sommeria and Deardorff 1977). This quantity is used by some existing parametrizations to diagnose cloud fraction and cloud condensate (e.g. Cuijpers and Bechtold 1995; Cusack et al. 1999). Chaboureau and Bechtold (2002) proposed to extend its use to all convective clouds, by applying a parametrization based on a first-order turbulent closure that allows diagnosis of the cloud cover. This quantity is very close to the NSD (not shown) for the present case. It would thus be useful to investigate further the way in which the NSD can

* Not to be confused with the apparent heat source also noted $Q_{1}$ introduced by Yanai et al. (1973). 
be introduced into the convection scheme, in order to represent the convective regimes described above.

\section{ACKNOWLEDGEMENTS}

This research was supported by the European Cloud System (EUROCS) project, funded by the European Commission under the contract EVK2-1999-00322. The authors acknowledge the help of Patrick Jabouille in the Meso-NH simulations, the extensive comments by Jun-Ichi Yano, and comments from Steve Derbyshire and reviewers.

Bechtold, P., Chaboureau, J.-P., Beljaars, A., Betts, A. K., Köhler, M., Miller, M. and Redelsperger, J.-L.

Bony, S. and Emanuel, K.

Bougeault, P. and Lacarrère, P.

Brown, R. G. and Zhang, C.

Chaboureau, J.-P. and Bechtold, P.

Cuijpers, J. W. M. and Bechtold, P.

Cusack, S., Edwards, J. M. and Kershaw, R.

Cuxart, J., Bougeault, P. and Redelsperger, J.-L.

Dai, A., Giorgi, F. and Trenberth, K. E.

Duvel, J.-P.

Gregory, D., Morcrette, J.-J., Jakob, C., Beljaars, A. M. and Stockdale, T.

Guichard, F., Petch, J. C.,

Redelsperger, J.-L.,

Bechtold, P.,

Chaboureau, J.-P., Cheinet, S. Grabowski, W., Grenier, H., Jones, C. G., Köhler, M., Piriou, J.-M., Tailleux, R. and Tomasini, $\mathrm{M}$.

Lafore, J.-P., Stein, J., Asencio, N., Bougeault, P., Ducrocq, V., Duron, J., Fischer, C., Héreil, P., Mascart, P., Masson, V., Pinty, J.-P., Redelsperger, J.-L.,

Richard, E. and Vilà-Guerau de Arellano, J.

Lin, X., Randall, D. A. and Fowler, L. D.

\section{REFERENCES}

2004 The simulation of the diurnal cycle of convective precipitation over land in a global model. Q. J. R. Meteorol. Soc., 130, 3119-3137

2001 A parameterization of the cloudiness associated with cumulus convection; Evaluation using TOGA COARE data. J. Atmos. Sci., 58, 3158-3183

1989 Parameterization of orographic induced turbulence in a mesobetascale model. Mon. Weather Rev., 117, 1872-1890

1997 Variability of midtropospheric moisture and its effect on cloud-top height distribution during TOGA COARE. J. Atmos. Sci., 54, 2760-2774

2002 A simple cloud parameterization derived from cloud resolving model data: diagnostic and prognostic applications. J. Atmos. Sci., 59, 2362-2372

1995 A simple parameterization of cloud water related variables for use in boundary layer models. J. Atmos. Sci., 52, 2486-2490

1999 Estimating the subgrid variance of saturation, and its parametrization for use in a GCM cloud scheme. Q. J. R. Meteorol. Soc., 125, 3057-3076

2000 A turbulence scheme allowing for mesoscale and large-eddy simulations. Q. J. R. Meteorol. Soc., 126, 1-30

1999 Observed and model simulated precipitation diurnal cycle over the contiguous united states. J. Geophys. Res., 104, 63776402

1989 Convection over tropical Africa and the Atlantic Ocean during northern summer. Part I: Interannual and diurnal variations. Mon. Weather Rev., 117, 2782-2799

2000 Revision of convection, radiation and cloud schemes in the ECMWF model. Q. J. R. Meteorol. Soc., 126, 1685-1710

2004 Modelling the diurnal cycle of deep precipitating convection over land with cloud-resolving models and single-column models. Q. J. R. Meteorol. Soc., 130, 3139-3172

1998 The Meso-NH Atmospheric Simulation System. Part I: adiabatic formulation and control simulations. Scientific objectives and experimental design. Ann. Geophys., 16, 90-109

Diurnal variability of the hydrologic cycle and radiative fluxes: Comparisons between observations and a GCM. J. Climate, 13, 4159-4179 
Mapes, B. E.

Mellor, G. L.

Mlawer, E. J., Taubman, S. J., Brown, P. D., Iacono, M. J. and Clough, S. A.

Nesbitt, S. W. and Zipser, E. J.

Parsons, D. B., Yoneyama, K. and Redelsperger, J.-L.

Petch, J. C., Brown, A. R. and Gray, M. E. B.

Pinty, J.-P. and Jabouille, P.

Price, J. D. and Wood, R.

2002

Redelsperger, J.-L., Parsons, D. B. and Guichard, F.

Sherwood, S. C.

Sommeria, G. and Deardorff, J. W.

Tompkins, A. M.

2002

Wallace, J. M.

1975

Xie, S., Cederwall, R. T.,

Xu, K.-M., Bechtold, P.,

Cripe, D. G., Del Genio, A. D.,

Ghan, S. J., Gregory, D.,

Hack, J. J., Iacobellis, S. F.,

Klein, S. A., Krueger, S. K.,

Lohmann, U., Petch, J. C.,

Randall, D. A.,

Rotstayn, L. D.,

Somerville, R. C. J.,

Sud, Y. C., von Salzen, K.,

Walker, G. K., Wolf, A.,

Yio, J. J., Zhang, G. and Zhang, M.

Xu, K.-M., Cederwall, R. T.,

Donner, L. J.,

Grabowski, W. W.,

Guichard, F., Johnson, D. E.,

Khairoutdinov, M.,

Krueger, S. K., Petch, J. C.,

Randall, D. A., Seman, C. J.,

Tao, W.-K., Wang, D.,

Xie, S. C., Yio, J. J. and

Zhang, M.
Convective inhibition, subgrid-scale triggering energy, and stratiform instability in a toy tropical wave model. J. Atmos. Sci., 57, 1515-1535

The gaussian cloud model relations. J. Atmos. Sci., 34, 356-358

Radiative transfer for inhomogeneous atmospheres: RRTM, a validated correlated-k model for the longwave. J. Geophys. Res., 102D, 16663-16682

The diurnal cycle of rainfall and convective intensity according to three years of TRMM measurements. J. Climate, 16, 14561475

The evolution of the tropical western Pacific atmosphere-ocean system following the arrival of a dry intrusion. Q. J.R. Meteorol. Soc., 126, 517-548

The impact of horizontal resolution on convective development in simulations of the diurnal cycle over land. Q. J. R. Meteorol. Soc., 128, 2031-2044

'A mixed-phase cloud parameterization for use in a mesoscale non-hydrostatic model: simulations of a squall line and of orographic precipitations.' Pp. 217-220 in Proceedings of the AMS conference on cloud physics, 17-21 August 1998, Everett, WA, USA

Comparison of probability density functions for total specific humidity and saturation deficit humidity, and consequences for cloud parametrization. Q. J. R. Meteorol. Soc., 128, 2059-2072

Recovery processes and factors limiting cloud-top height following the arrival of a dry intrusion observed during TOGA COARE. J. Atmos. Sci., 59, 2438-2457

Convective precursors and predictability in the tropical western Pacific. Mon. Weather Rev., 127, 2977-2991

Subgrid-scale condensation in models of nonprecipitating clouds. J. Atmos. Sci., 34, 344-355

A prognostic parameterization for the subgrid-scale variability of water vapor and clouds in large-scale models and its use to diagnose cloud cover. J. Atmos. Sci., 59, 1917-1942

Impact of temperature and humidity variability on cloud cover assessed using aircraft data. Q. J. R. Meteorol. Soc., 129, 2151-2170

Diurnal variations in precipitation and thunderstorm frequency over the conterminous United States. Mon. Weather Rev., 103, 406-419

2002 Intercomparison and evaluation of cumulus parametrizations under summertime midlatitude continental conditions. Q. J. R. Meteorol. Soc., 128, 1095-1135

2002 An intercomparison of cloud-resolving models with the ARM summer 1997 IOP data. Q. J. R. Meteorol. Soc., 128, 593624 
Yanai, M., Esbendsen, S. K. and Chuh, J.-H.

Yang, G.-Y. and Slingo, J. Zhang, M. H. and Lin, J. L.
1973 Determination of bulk properties of tropical cloud clusters from large-scale heat and moisture budgets. J. Atmos. Sci., 30, 611-627

2001 The diurnal cycle in the tropics. Mon. Weather Rev., 129, 784-801

1997 Constrained variational analysis of sounding data based on column-integrated budgets of mass, heat, moisture, and momentum: approach and application to ARM measurements. J. Atmos. Sci., 54, 1503-1524 